\title{
Has Britain solved its teenage pregnancy problem?
}

In this article by Sophie Arie, we wrongly stated that CARE (Christian Action Research Education) was invited to join the government's sexual health forum (BMJ 2014;348:g2561, doi:10.1136/bmj.g2561). Additionally, we spelt the University of Bedfordshire incorrectly.

Clarification-We would like to clarify that the government closed the teenage pregnancy unit in 2012, and a Labour proposed amendment to a bill, which would have made sex and relationship education compulsory, was blocked by the coalition in 2013. The Netherlands and Sweden do not have the lowest teenage pregnancy rates in the developed world; they are among the five developed countries with the lowest rates according to the latest comparative data.

Cite this as: BMJ 2014;348:g2869

๑ BMJ Publishing Group Ltd 2014 